\title{
Professional caregivers' knowledge, beliefs and attitudes about awareness in advanced dementia: A systematic review of qualitative studies.
}

Running title: Caregivers' beliefs about awareness in advanced dementia

Rice, $\mathrm{H}^{1}$., Howard, $\mathrm{R}^{2}$., Huntley, $\mathrm{J}^{2 *}$.

Author's Accepted Manuscript

${ }^{1}$ Imperial College NHS Foundation Trust, London UK, ${ }^{2}$ Division of Psychiatry, University College London, UK

*corresponding author: Dr Jonathan Huntley, Division of Psychiatry, University College London, email: j.huntley@ucl.ac.uk 


\begin{abstract}
Objectives: Awareness can be defined as a response to, or evaluation of, an aspect of one's situation or internal state. Awareness becomes impaired as dementia progresses, however the exact nature and degree of impairment in advanced dementia remains unclear. The extent to which caregivers understand or make assumptions about the level and nature of awareness in advanced dementia may have a significant impact on their ability to appropriately respond to and care for the person with dementia. This systematic review examines the literature regarding professional caregiver perceptions about awareness in advanced dementia.
\end{abstract}

Design: A systematic search of online literature databases (PsychInfo, Medline, Embase, CINAHL) was conducted up to $15^{\text {th }}$ January 2018 , using a range of search terms related to dementia, awareness and caregiver attitudes.

Results: The systematic review included a total of 10 qualitative studies that were heterogeneous in aspects of design, including analyses. Narrative synthesis was used to integrate results. Four major themes were identified from review of the papers: how professional caregivers defined awareness; professional caregiver beliefs about what influences the expression of awareness; professional caregiver beliefs around how to assess awareness in advanced dementia; and the perceived impact of episodes of increased awareness on the person with dementia and caregiver. Sub-themes were identified within each of these areas.

Conclusion: This review highlights the importance of professional caregiver perceptions of awareness in advanced dementia. Supporting professional caregivers to assess and understand the nature of awareness in advanced dementia would improve their approach to care and outcomes for people with dementia.

Keywords: Awareness; Advanced Dementia; Caregiver; 


\section{Introduction}

An estimated 35.6 million people live with dementia worldwide; a number that is anticipated to double every 20 years (World Health Organisation 2012). There is an urgent need to understand the lived experience of people with dementia in order to develop appropriate health and care services that are responsive to need (Lawton 1994; Kitwood 1997; Innes \& Surr 2001; O'Connor et al. 2007; Edvardsson et al. 2008) Understanding what a person with dementia subjectively experiences requires an understanding of the nature and extent of awareness in dementia. Awareness can be defined as 'the ability to hold a reasonable or realistic perception or appraisal of, and/or respond accordingly to, a given aspect of one's environment, situation, functioning or performance. This ability may be expressed explicitly, through direct self-report, or implicitly, through behaviour' (Clare 2010). Clare (2011) distinguishes between lower level or core aspects of awareness that relate to sensory registration, and higher levels of awareness that require performance monitoring, evaluative judgement and meta-representation (Clare et al. 2011).

Much of the literature on awareness in dementia has focused on mild to moderate disease (Clare et al. 2005). Awareness of such disparate constructs as diagnosis, performance on activities of daily living tasks and more complex considerations such as metacognition and evaluative judgement have all been shown to be affected in dementia (Green et al. 1993; Duke et al. 2002; Cotrell \& Wild 1999). Awareness in advanced dementia has, however, received comparatively little empirical attention. Issues with measurement, and a traditional reliance on language in assessment present a methodological challenge. However, whilst verbal communication is often impaired in this patient group, emotional feelings and needs are thought to be preserved, alongside the ability to express those needs in some form (Magai et al. 1996; Clare 2010).

Dementia is progressive and people with dementia spend on average $40 \%$ of their time in the advanced or 'severe' stage of the disease (Knapp et al. 2007). At this stage there is severe cognitive and functional impairment, often necessitating fulltime care in specialist care homes, and many people with advanced dementia therefore receive most of their care from professional caregivers. Questions of how professional caregivers view the level of awareness of the people with dementia they care for are critical for ensuring the provision of personcentred care. There is only a limited literature exploring the extent and nature of awareness in advanced dementia, with a focus on eliciting signs of 'lower level' sensory awareness (Clare 2010). Behavioural responses, such as eye movements and change in facial expression, vocalisations and body movement in response to different environmental stimuli, have all been observed (Clare et al. 2012). Furthermore, the degree and nature of such responses has been 
shown to be associated with the nature of the external stimuli, for example in response to music, touch or object presentation (Norberg et al. 1986). There is also some evidence to suggest that people with severe dementia who are able to verbalise may have some capacity for more higher-level awareness including self-reflection on significant aspects of their situation, for example the loss of a spouse, or the approach of death (Clare et al. 2008). Environmental and social factors have been recognised as important determinants for the expression of awareness in advanced dementia, including the style of the caregiver's approach, and a caregiver's ability to elicit signs of awareness (Aalten et al. 2005; Clare 2010). The more caregivers can acknowledge and anticipate awareness of self, functioning and performance by a person with advanced dementia, the better positioned they will be to provide high quality, appropriate care and support. There is relatively little research on caregiver, and particularly professional caregiver (e.g. nurses, doctors, healthcare assistants) knowledge, attitudes and beliefs about awareness in dementia. The impact of such beliefs holds pertinence in relation to caring for people with advanced dementia, given their increased dependence upon caregivers and the limited clinical findings around awareness at this dementia stage. The aim of this review is therefore to establish what is known from existing literature about professional caregivers' perceptions about awareness in advanced dementia. 


\section{Methods.}

\section{Search strategy:}

A scoping search of the PROSPERO database and Cochrane library was completed and identified that there were no pre-existing systematic reviews or planned systematic reviews on this topic. A systematic search of online literature databases (PsychInfo, Medline, Embase, CINAHL) was conducted up to $15^{\text {th }}$ January 2018 to identify studies, using the search terms in Box 1. Reference lists of relevant results were also searched for additional studies. Inclusion criteria included primary research, in English and related to professional caregivers' knowledge, attitudes or beliefs about awareness in advanced dementia. Studies that directly examined caregivers' knowledge about awareness in advanced dementia, and studies that indirectly assessed caregivers' beliefs about a relevant aspect of awareness in advanced dementia were considered for inclusion. As the focus of the review is on professional caregivers, studies assessing awareness without reference to the attitudes of professional caregivers, or only describing the opinions of family caregivers or primary researchers were excluded. Studies that did not explicitly describe awareness in people with advanced dementia, and only discussed awareness in people with mild-moderate dementia were also excluded.

\section{Box 1: Search terms}

1) Professional OR carer* OR team OR MDT OR psychiatrist OR neurologist OR nurse OR therapist OR worker OR assistant OR staff

AND

2)AD OR Dem* OR alzheimer* OR "vascular dementia" OR "mixed dementia" OR "frontotemporal dementia" OR FTD OR "lewy body disease" OR LBD OR DLB AND

3) Aware* OR Conscious* OR anosognosia OR subjective OR QOL OR insight AND

4) Attitude OR opinion OR view OR belief

AND

5) Survey OR qualitative OR review OR questionnaire

\section{Synthesis methodology:}

Narrative synthesis was utilised to integrate and appraise the findings of this systematic review. This method allows the inclusion of different types of study designs within one framework, notably quantitative and qualitative literature (Snilstveit et al. 2012), and the inclusion of studies using different methodological approaches within the qualitative paradigm (e.g. thematic analysis, phenomenological hermeneutic). Three broad stages of analysis were completed within this systematic review (Oliver et al. 2005); study classification, study 
comparison and thematic analysis of findings. Two authors (HR and JH) reviewed potential studies for inclusion and consensus for inclusion was reached by discussion. Thematic analysis was performed as an iterative process. Studies were read and re-read by the researchers and key themes were identified for each paper and then amalgamated and integrated across studies. As study quality did not dictate inclusion in the review, formal assessment of study quality was not included.

\section{Results:}

A total of 4674 search results were identified. 4625 were excluded from review of the abstract due to irrelevance, 42 were excluded after review of the full article. A total of seven papers were included in the review from the database search. Three additional papers were identified from handsearching of reference lists of key papers. A total of ten papers were therefore included in the review (see Figure 1 and Table 1).

\section{Study classification and comparison}

Included papers are heterogeneous in terms of their design and methodology (Table 1). Three papers considered the construct of awareness within wider studies of professional carer views of their day-to-day duties (Berg et al. 1998; Rasmussen \& Hellzen 2013; Pasman et al. 2003). Four papers considered the impact of a particular intervention (that includes some relevance to awareness) on professional caregivers approach to care provision (Hansebo \& Kihlgren 2001; Alnes et al. 2011; Clare et al. 2013; Nicholls et al. 2013). Three papers (Normann et al. 1998; Quinn et al. 2014; Karger 2018) considered awareness or a related construct directly. Papers differed in both the participants and setting of the studies. Participants included registered nurses and other professionals such as doctors or health care assistants. Nurses were best represented in study sampling, forming all or part of the sample in seven out of the ten studies. Sample sizes varied significantly, from 4 (Hansebo \& Kihlgren 2001), to 64 (Clare et al. 2013). One study was based in a hospital environment (Berg et al. 1998) whilst the remainder were conducted in nursing home or dementia care settings (Alnes et al. 2011; Hansebo \& Kihlgren 2001; Normann et al. 1998; Clare et al. 2013; Quinn et al. 2014; Karger 2018; Nicholls et al. 2013; Pasman et al. 2003).

Studies varied in the methods of analysis. Three studies employed a phenomenological hermeneutic approach (Berg et al. 1998; Hansebo \& Kihlgren 2001; Rasmussen \& Hellzen 
2013), three used content analysis (Normann et al. 1998; Alnes et al. 2011; Karger 2018), three used thematic analysis (Clare et al. 2013; Quinn et al. 2014; Nicholls et al. 2013), and one used constant comparison analysis (Pasman et al. 2003).

\section{Thematic analysis}

A total of four major themes were identified across the papers pertaining to 1) how professional caregivers defined awareness as a construct; 2) professional caregivers' beliefs about what influenced changes in awareness and supported its expression, 3) issues around the assessment of awareness and 4) the impact of episodes of increased awareness. Within each major theme, several associated sub-themes were also identified (table 2). Given the complexity and interrelated nature of awareness itself as a construct, despite attempts to delineate major themes, some degree of overlap was considered unavoidable.

\section{1) How caregivers understand and define awareness}

The first theme focused on how professional caregivers defined awareness. Several subthemes were identified regarding understanding awareness as related to different objects, namely the self, other people and to the environment.

Quinn et al. (2014) noted that professional caregivers were more likely than family members to make a global judgement about whether a person with advanced dementia was aware or unaware, viewing awareness as a unitary phenomenon and as being either present or absent. Quinn et al. (2014) assert that this may have negative implications for the approach of caregivers and potential isolation of the person with dementia, however several themes also emerged regarding caregivers defining awareness according to the object of awareness.

\section{Awareness of self}

Awareness of the self was understood by caregivers as a capacity of the person with dementia to have an experience of emotion or pain, or some awareness of their pre-morbid identity, personality and life experience, or of current function and diagnosis. The experience of emotion by the person with advanced dementia was highlighted by several studies as being perceived as a key component of awareness by professional caregivers (Berg et al. 1998; Normann et al. 1998; Quinn et al. 2014). In Berg et al. (1998), for example, one nurse noted when describing her experience of caregiving for a person with advanced dementia 'If you make a joke, you realise that they are there with you, they laugh and smile'. Significantly, 
caregiver accounts gave examples of people with advanced dementia expressing a range of emotion from humour to irritation, and from unhappiness to fear, which corresponds with other studies that have asked family and professional caregivers to quantitatively score emotional expression in people with advanced dementia (Magai et al. 1996). The experience or expression of pain was also a key component of awareness within Quinn et al.'s (2014) study, which noted that professional caregivers felt that signs of pain formed part of their understanding of what constituted awareness in people with advanced dementia. One study (Rasmussen \& Hellzen 2013), acknowledged that caregivers understood awareness as relating to aspects of the self that included a person's awareness of their functional ability and diagnosis. Caregivers' understanding of awareness of self in people with advanced dementia was also related to the preserved expression of pre-morbid personality traits. Berg et al. (1998), for example, noted that dementia nurses understood behaviours of people with advanced dementia within the context of their pre-morbid personality and life history. If a behaviour of a person with advanced dementia was assessed as consistent with their pre-morbid personality, caregivers then interpreted this as a sign of awareness (Quinn et al. 2014). Similarly, in an intervention using objects such as dolls to encourage touch, carers interpreted the response to the doll by the person with dementia as associated with a retained aspect of their previous role as a parent or carer (Nicholls et al. 2013)

\section{Social awareness}

Awareness of others also emerged as a key component of awareness across studies (Hansebo \& Kihlgren 2001; Quinn et al. 2014; Clare et al. 2013; Nicholls et al. 2013; Karger 2018). Professional caregivers within Hansebo and Kihlgren's (2001) study reported that they felt that people with an advanced dementia were made aware of them as caregivers by their movement, the style of touch they employed and the tone of voice they used. Moreover, professional caregivers felt such awareness had an impact on the quality and nature of the care interaction. Interestingly, professional caregivers reported that people with an advanced dementia have an increased sensitivity to touch as a means of communicating with others (Hansebo \& Kihlgren 2001). In a study examining the role of touch, based on the Namaste Care Programme, caregivers reported that the use of touch and affectionate language reminded them that people with end-stage dementia were capable of emotional reciprocity (Nicholls et al. 2013). Some caregivers identified that an important component of awareness was an ability to respond and react to elements of the caregiver's personality, mood and behaviour (Quinn et al. 2014). For example, some caregivers reported that people with advanced dementia were aware when care 
staff were having an 'off day', due to changes in their behaviour and style of interaction (e.g. being more rushed during personal care). Similarly, in Karger's (2018) study caregivers' expressed that people with advanced dementia retained the capacity to be emotionally aware of a caregiver's mood and to differentiate sincere attention from insincere attention. One caregiver is quoted as stating 'I sense that this world of feelings is very well-developed....They know immediately if I am not being authentic'. The professional caregivers interviewed by Karger also concluded that people with advanced dementia were still able to recognize and connect both positive and negative emotions with individuals (Karger 2018). Within Quinn et al.'s (2014) focus groups, the ability of a person with advanced dementia to actively recognise those around them; specifically, family members and familiar professional caregivers; also emerged as a key component of awareness.

\section{Awareness of the environment}

Quinn et al. (2014) found that professional caregivers often considered that people with advanced dementia were not aware of aspects of their physical environment. Several caregivers reported instances of people with an advanced dementia bumping in to doorframes; interpreted as a lack of environmental awareness. Professional caregivers also expressed a view that people with an advanced dementia did not have an awareness of where they were (when situated in a care home environment) but, interestingly, generally felt that they were aware that they were somewhere other than their own home. Normann et al.'s (1998) study, which focussed on professional caregiver descriptions of episodes of increased awareness (referred to as lucidity) in people with advanced dementia, included one caregiver account of a man with advanced dementia who, whilst out on an organised trip, wandered off and successfully directed himself to a nearby coffee shop where his daughter worked (known to him pre-morbidly) in search of a drink. This was interpreted by caregivers as an unusual instance of a person with advanced dementia being oriented to a pre-morbidly familiar geographical area, and was interpreted as an exceptional expression of heightened awareness, rather than a caregiver's perception of what is usual in advanced dementia.

\section{2) Factors influencing the expression of awareness}

Caregiver perceptions regarding the influences or determinants of awareness in advanced dementia was the second main theme identified across the included studies, with the significance of caregiver approach most represented within papers. Sub-themes around the 
influence of disease progression, the physical environment and fluctuating nature of awareness were also identified.

The perceived impact of disease progression on the expression of awareness was expressed in one study, as illustrated by a caregiver comment 'A gravely demented person sort of disappears...'. (Berg et al. 1998). This suggests that some caregivers expect reduced awareness to occur with the progression of dementia to an advanced stage. Caregiver perceptions of the impact of the physical environment on the expression of awareness was directly assessed by one study. Quinn et. al. (2014) found that caregivers believed that the expression of awareness could be influenced by aspects of the physical environment, with high levels of noise or commotion perceived to be associated with increased difficulty in expressions of awareness in people with advanced dementia.

Apparently random variability in awareness was also acknowledged. In Quinn et. al. (2014) one professional reflected ' With a lot of them (residents)... it's more luck than judgement if you know what I mean...You've got them on a good day and they will respond to that but they won't respond to it tomorrow... what they do today they might not do tomorrow.', illustrating a perception that awareness was often inconsistent. Rasmussen and Hellzen, (2013) also included caregiver reports of short-lived episodes of increased awareness (lucidity or 'clear moments'). Caregivers' understanding of this generally focussed around people with an advanced dementia having 'good days' and 'bad days', and as such, that their awareness fluctuated across days, and even during the same day.

The approach or knowledge of the professional caregiver as an influencing factor on the expression of awareness in people with an advanced dementia was directly addressed within two studies (Rasmussen \& Hellzen 2013; Alnes et al. 2011). Alnes et. al. (2011) found that the caregiving interaction was a determinant of the expression of awareness in people with advanced dementia. In particular, one nurse reflected that the person with dementia's awareness was negatively affected if the demands placed on them were too rapid, complex or distracting. Similarly, Rasmussen and Hellzen (2013) reported that episodes of increased awareness often emerged when caregivers put no 'demand' on the patient, and also when caregivers knew more about the underlying personality and life experience of the person with advanced dementia

Caregivers also thought that the expression of awareness was also related to whom the person with dementia was interacting with, with a greater degree of awareness displayed during interactions with close family members compared to care staff (Quinn et al. 2014). 


\section{3) Caregivers' assessment of awareness}

The third, related key theme within the included studies is how professional caregivers attempt to elicit signs of, or assess, the presence of awareness in people with advanced dementia (Quinn et al. 2014; Hansebo \& Kihlgren 2001; Berg et al. 1998; Clare et al. 2013). Indeed, a key consideration noted within the paper by Hansebo and Kihlgren (2001) was difficulties that professional caregivers experienced in assessing awareness, and as such understanding the inner world of the person with dementia. As one professional caregiver reflected 'You know so little about how much they understand; you know nothing really... '. Professional caregivers noted that assessment of verbal and non-verbal cues, within a context of knowledge about the situation and history of the person with dementia were key elements to assessing patient awareness of aspects of their lived experience (Hansebo \& Kihlgren 2001). Caregivers reported that eye contact, facial expression, bodily movement and bodily tension were all recognised as significant indicators of awareness in a person with advanced dementia who had lost speech (Berg et al. 1998). For example, one caregiver in Clare et al. (2013) is quoted as stating 'She does respond... A lot of eye movements and turning her head, and if you suddenly touch her and she hasn't seen you she jumps.. She is very aware'. The use of such non-verbal cues including eye contact and facial expression to assess social awareness, is illustrated by a caregiver reporting: 'It's just a flicker isn't it, a slight flicker .......and they lock eyes with you don't they', '...he's got a lovely sparkle in his eyes. That helps me to know he's, he's connected with something, he's linked up with something.' (Quinn et al. 2014). Similarly, caregivers in Karger's (2018) study reported that observing non-verbal factors such as facial expressions, gestures and eye movements allowed them to assess the social awareness of people with severe dementia (Karger 2018).

Other behaviours such as wandering, vocalizing, shouting or aggression, were also assessed as expressions of awareness in response to stimuli, and caregivers reported attempting to understand such expressions as due to underlying factors such pain, fear, and premorbid personality and role. The knowledge that caregivers had of the person with advanced dementia was again also seen to be key in determining and interpreting signs of awareness. For example, a participant in Quinn et al. (2014) reported 'I think it's more on how you learn to, as you say, like read them than them actually telling you all'. A key element of the assessment of awareness based on observations of emotional or behavioural response was the caregiver's judgement of whether an emotion expressed was a reasonable response to some aspect of the situation or internal state of the person with dementia. Responses judged as appropriate or reasonable were interpreted as constituting an expression of awareness. However, in Karger's 
(2018) study it was reported that even though caregivers recognised the importance of being familiar with the biographical history of a person with dementia to correctly interpret their behaviour, positive facial expressions or behaviour was more readily interpreted as reflecting underlying congruent awareness, leading to Karger cautioning that 'self-serving attributions by professional caregivers can lead to an overinterpretation of nonverbal (behaviour)' (Karger 2018). The issue of the significant variability in caregivers' interpretations or 'intuitions' of whether a behaviour was due to awareness or not was raised in a study assessing caregivers' beliefs around feeding people with severe dementia. Caregivers' interpretations of a person with severe dementia being unwilling to eat ranged from belief that the person with dementia was aware enough to reject food as they did not want to live, to believing the person with dementia was unaware of the food as food. This highlights the issue of assessing awareness through interpreting behaviour and the uncertainties experienced by caregivers (Pasman et al. 2003).

\section{Impact of training}

Clare et al (2013), Alnes et al. (2011) and Hansebo and Kilhgren (2001) all considered the impact of staff training interventions on practice in dementia care. Clare et al. (2013) reported the results of a pilot study of an intervention to improve the ability of professional caregivers to observe people with severe dementia and recognise signs of awareness. Staff were trained to use the AwareCare observational measure (Clare et al. 2012) and then conducted an average of twenty, ten-minute observations over a six-week period. The training and intervention brought about significant changes in an objective measure of family-related quality of life for the people with dementia, and also a change in attitudes of caregivers towards the people they observed. Caregivers are quoted as moving from a position of describing the people with dementia as 'boring' and not 'doing anything' before training to subsequently referring to the same people as 'very aware', reflecting the impact of training on their perception of awareness in people with advanced dementia (Clare et al. 2013). The main focus of the study by Alnes et al. (2011) was to consider the impact of Marte Meo counselling, an intervention that aims to assist staff to recognise their own communication style and then assist them to communicate more effectively with people with dementia. One of the main findings of this study was that after the counselling intervention, caregivers felt that the people with dementia they supported could comprehend, or were significantly more aware than they had previously thought. In particular, nurses felt that they were better equipped, post-counselling intervention, to notice signs of awareness in this patient group. Hansebo and Kihlgren (2001) considered the impact 
of a one-year intervention focused on clinical supervision to support person-centred care delivery. The study found that professional carers showed an increased knowledge of the way that person-centred care could support the expression of awareness in people with advanced dementia.

\section{4) The effects of episodes of increased awareness}

The fourth main theme across included papers was a description of episodes of 'lucidity' or increased awareness. The focus of Normann et. al.'s (1998) paper is the exploration of professional caregivers' narrations of episodes of lucidity in people with advanced dementia. Additionally, Alnes et al. (2011), Rasmussen and Heltzen (2013) and Quinn et al. (2014) all acknowledge the existence and impact of such episodes. Episodes of increased lucidity were seen to have an impact on both the person with dementia and the professional caregiver. Three studies included reference to the unexpected nature of episodes of increased awareness in people with advanced dementia (Normann et al. 1998; Alnes et al. 2011; Rasmussen \& Hellzen 2013). Normann et al. (1998) for example, report that many caregivers saw such episodes of increased awareness as surprising. Similarly, caregivers reported surprise at apparent increased awareness in people with advanced dementia as a result of an altered care approach (Alnes et al. 2011). Interestingly, several studies also report the positive way in which such episodes of increased lucidity can impact on professional caregivers. Rasmussen and Heltzen (2013) for example, report caregiver comments of responses of 'joy and astonishment amongst the staff members...'. Within this study, professional caregivers believed these episodes of lucidity were associated with increased quality of life of the person with dementia and were also valuable in developing a connection between the caregiver and patient and resulting in better care. In themselves, episodes of increased awareness are also reported as a reward for some staff, in terms of feelings of a job well done. Such episodes of increased awareness are also described as a motivator to continue working with the person with dementia. In contrast, caregivers also reported some negative responses to episodes of apparent increased awareness (Quinn et al. 2014; Rasmussen \& Hellzen 2013; Normann et al. 1998). Negative responses seemed to be associated with the unexpectedness of the episode. Normann et al. (1998) reports that some caregivers were 'terribly frightened' as the behaviour of the person with dementia was unexpected and as such unpredictable. Other accounts related more to the nature of such episodes of increased lucidity, such as a negative caregiver experience of a person with dementia becoming distressed following increased awareness of their condition and current 
situation (Rasmussen \& Hellzen 2013). Similarly, caregivers within Quinn et al.'s (2014) focus group reported that increased awareness in a person with an advanced dementia could potentially be negative if related to awareness of diagnosis or aspects of deterioration in health.

\section{Discussion}

The four major themes of professional caregiver's knowledge and beliefs about awareness in advanced dementia identified in this review map on to what has been identified in theoretical models of awareness in dementia. For example, a key sub-theme identified from the review is that professional caregivers considered awareness as a relational construct, that is, something experienced with regard to a particular aspect of one's situation or lived experience. Across and within the included papers, caregivers described their understanding of awareness in advanced dementia as relating to a number of 'objects' of awareness, identified in sub-themes as awareness of the self, social awareness and awareness of the environment. This is consistent with Markova and Berrios' (2001) model of awareness which describes the relational aspects of the experience of awareness as key to understanding the phenomenon (Markova \& Berrios 2001). Interestingly, there are limited findings within the review relating to caregiver understanding of the potential impact of the complexity of the object of awareness or the complexity of the response that may be expected in a person with advanced dementia, in line with Clare et al.'s Levels of Awareness framework (Clare et al. 2011). Establishing caregivers' beliefs about the capacity for people with advanced dementia to experience more higher-level awareness would be an important consideration for future research.

Of note the literature reflects research over a significant timeframe. During this time there have been significant advances in person-centred approaches to care (Kitwood 1997) and this is potentially reflected in the difference in language from the earlier papers (e.g. Berg 1998 containing quotes from carers that ' a gravely demented person sort of disappears') compared to more recent studies that stress the importance of improving caregivers' understanding about awareness in people with dementia to improve their quality of care (Clare et al. 2013; Quinn et al. 2014). However it is notable that despite the positive influence of person-centred care and specific programs such as Namaste Care (Nicholls et al. 2013), there remains limited literature and consensus on how professional caregivers understand the awareness of the people with advanced dementia they care for. This review identified important themes relating to enhancing the assessment and expression of awareness and the impact of episodes of increased lucidity on professional caregivers (Normann et al. 1998; Alnes et al. 2011; Rasmussen \& 
Hellzen 2013). Such findings indicate that supporting increased awareness in advanced dementia has the potential to be a rewarding and motivating experience for professional caregivers, and that caregivers perceive benefits for the person with dementia in terms of improved quality of life. Supporting caregivers to recognise signs of awareness in advanced dementia may support the caregiver-patient relationship and facilitate the delivery of high standards of care, and training interventions may facilitate these positive outcomes (Hansebo \& Kihlgren 2001; Alnes et al. 2011; Clare et al. 2013). There is therefore a need to prioritize such training interventions in future research.

There are several limitations to the review. Firstly, although it was possible to identify themes across the included studies, some sub-themes, for example, the influence of the physical environment and disease progression on expression of awareness in dementia, were reliant upon findings from only one or two papers. This is perhaps expected given the small number of studies included in the review and the variety of research questions that they addressed, however it emphasises the lack of research in this area and the need for future research.

Secondly, whilst all the studies utilised a qualitative approach, there was significant heterogeneity in terms of the research questions, data collection, data analysis methods (e.g. phenomenological hermeneutic, thematic analysis), sample sizes, settings and locations of the studies (Table 1). The use of narrative synthesis and thematic analysis is an adaptive framework within which to address such methodological challenges. Moreover, given the lack of relevant studies that have addressed caregiver perceptions around awareness in advanced dementia, it would not have been feasible to apply any strict inclusion/exclusion criteria that reduced such heterogeneity. The small number of included studies were all based in Western Europe, apart from one study from Australia, which highlights both the paucity of research and a potential lack of cultural diversification. Despite these methodological limitations the review highlights the key themes around professional caregiver perception of awareness in advanced dementia present within the existing literature.

\section{Conclusion.}

This systematic review of professional caregiver perceptions about awareness in advanced dementia highlights key themes, notably the way that professional caregivers understand and define awareness in dementia, their understanding of important influences on the expression of awareness in dementia, key components in the assessment of awareness and the perceived impact of increased awareness on both the person with dementia and the professional caregiver. There may be particular value in further elucidating the expression and impact of episodes of 
increased awareness and how to train professional caregivers to appropriately assess and understand the nature of awareness in advanced dementia. Future research should also consider the potential applications of such findings to dementia care service and design, in particular with a view to caregiver training and approach that supports caregivers to understand the construct of awareness, recognise its signs and potential variance, as this may have a significant positive impact on quality of life of both caregivers and people with advanced dementia.

Conflict of interest declaration: none.

Description of authors' roles: JH and RH formulated the research question. JH and HR conducted the literature review and wrote the paper. RH assisted with writing the paper

Sponsor and Funding: JH is supported by a UCLH NHR Biomedical Research Centre postdoctoral fellowship.

\section{References}

Aalten, P. et al., 2005. Awareness in dementia: A review of clinical correlates. Aging \& Mental Health, 9(5), pp.414-422. Available at: https://doi.org/10.1080/13607860500143075.

Alnes, R.E., Kirkevold, M. \& Skovdahl, K., 2011. Insights gained through Marte Meo counselling: experiences of nurses in dementia specific care units. International journal of older people nursing, 6(2), pp.123-132.

Berg, A., Hallberg, I.. \& Norberg, A., 1998. Nurses reflections about dementia care, the patients, the care and themselves in their daily caregiving. International Journal of Nursing Studies, 35(5), pp.271-282. Available at: http://dx.doi.org/10.1016/S00207489(98)00040-6.

Clare, L. et al., 2013. AwareCare: a pilot randomized controlled trial of an awareness-based staff training intervention to improve quality of life for residents with severe dementia in long-term care settings. International Psychogeriatrics, 25(1), pp.128-139. Available at: https://www.cambridge.org/core/article/awarecare-a-pilot-randomized-controlled-trial- 
of-an-awarenessbased-staff-training-intervention-to-improve-quality-of-life-forresidents-with-severe-dementia-in-longterm-caresettings/214E5A4C75A7BC043448018F752EAD58.

Clare, L. et al., 2012. AwareCare: development and validation of an observational measure of awareness in people with severe dementia. Neuropsychological rehabilitation, 22(1), pp.113-133.

Clare, L. et al., 2011. Awareness in Alzheimer's disease and associated dementias: Theoretical framework and clinical implications. Aging \& Mental Health, 15(8), pp.936-944. Available at: https://doi.org/10.1080/13607863.2011.583630.

Clare, L. et al., 2005. Awareness in dementia: A review of assessment methods and measures. Aging \& mental health, 9(5), pp.394-413.

Clare, L., 2010. Awareness in people with severe dementia: Review and integration. Aging \& Mental Health, 14(1), pp.20-32. Available at: https://doi.org/10.1080/13607860903421029.

Clare, L. et al., 2008. "I don”t do like I used to do': A grounded theory approach to conceptualising awareness in people with moderate to severe dementia living in longterm care. Social Science \& Medicine, 66(11), pp.2366-2377. Available at: http://www.sciencedirect.com/science/article/pii/S0277953608000452.

Cotrell, V. \& Wild, K., 1999. Longitudinal study of self-imposed driving restrictions and deficit awareness in patients with Alzheimer disease. Alzheimer disease and associated disorders, 13(3), pp.151-156.

Duke, L.M. et al., 2002. Cognitive components of deficit awareness in Alzheimer's disease. Neuropsychology, 16(3), pp.359-369.

Edvardsson, D., Winblad, B. \& Sandman, P.O., 2008. Person-centred care of people with severe Alzheimer's disease: current status and ways forward. The Lancet. Neurology, 7(4), pp.362-367.

Green, J. et al., 1993. "Variable awareness of deficits in Alzheimer"s disease.'. Neuropsychiatry, Neuropsychology and Behavioral Neurology, 6(3), pp.143-207.

Hansebo, G. \& Kihlgren, M., 2001. Carers' reflections about their video-recorded interactions with patients suffering from severe dementia. Journal of clinical nursing, 10(6), pp.737-747.

Innes, A. \& Surr, C., 2001. Measuring the well-being of people with dementia living in formal care settings: the use of Dementia Care Mapping. Aging \& mental health, 5(3), pp.258-268. 
Karger, C.R., 2018. Emotional experience in patients with advanced Alzheimer's disease from the perspective of families, professional caregivers, physicians, and scientists. Aging \& Mental Health, 22(3), pp.316-322. Available at:

http://search.ebscohost.com/login.aspx?direct=true\&AuthType=ip,shib\&db=jlh\&AN=1 $27011031 \&$ site $=$ ehost-live $\&$ scope $=$ site.

Kitwood, T., 1997. The experience of dementia. Aging \& Mental Health, 1(1), pp.13-22. Available at: https://doi.org/10.1080/13607869757344.

Knapp, M. et al., 2007. Dementia UK: The full report,

Lawton, M.P., 1994. Quality of life in Alzheimer disease. Alzheimer disease and associated disorders, 8 Suppl 3, pp.138-150.

Magai, C. et al., 1996. Emotional Expression During Mid- to Late-Stage Dementia. International Psychogeriatrics, 8(3), pp.383-395. Available at: https://www.cambridge.org/core/article/emotional-expression-during-mid-to-latestagedementia/AD7F0AC1205C393C46A553ECA90FD786.

Markova, I.S. \& Berrios, G.E., 2001. The "object" of insight assessment: relationship to insight "structure". Psychopathology, 34(5), pp.245-252.

Nicholls, D. et al., 2013. Touch, the essence of caring for people with end-stage dementia: A mental health perspective in Namaste Care. Aging \& Mental Health, 17(5), pp.571-578. Available at: http://search.ebscohost.com/login.aspx?direct=true \&AuthType $=\mathrm{ip}, \operatorname{shib} \& \mathrm{db}=\mathrm{jlh} \& \mathrm{AN}=1$ $04185705 \&$ site $=$ ehost-live $\&$ scope $=$ site.

Norberg, A., Melin, E. \& Asplund, K., 1986. Reactions to music, touch and object presentation in the final stage of dementia: An exploratory study. International Journal of Nursing Studies, 23(4), pp.315-323.

Normann, H.K., Asplund, K. \& Norberg, A., 1998. Episodes of lucidity in people with severe dementia as narrated by formal carers. Journal of advanced nursing, 28(6), pp.12951300.

O'Connor, D. et al., 2007. Personhood in dementia care: Developing a research agenda for broadening the vision. Dementia, 6(1), pp.121-142. Available at: https://doi.org/10.1177/1471301207075648.

Oliver, S. et al., 2005. An Emerging Framework for Including Different Types of Evidence in Systematic Reviews for Public Policy. Evaluation, 11(4), pp.428-446. Available at: https://doi.org/10.1177/1356389005059383.

Pasman, H. et al., 2003. Feeding nursing home patients with severe dementia: a qualitative 
study. Journal of Advanced Nursing, 42(3), pp.304-311. Available at:

http://search.ebscohost.com/login.aspx?direct=true\&AuthType=ip,shib\&db=jlh\&AN=1 $06845170 \&$ site $=$ ehost-live $\&$ scope $=$ site.

Quinn, C. et al., 2014. "It"s in the eyes': how family members and care staff understand awareness in people with severe dementia. Aging \& Mental Health, 18(2), pp.260-268. Available at: https://doi.org/10.1080/13607863.2013.827627.

Rasmussen, H. \& Hellzen, O., 2013. The meaning of long-term caregiving for patients with frontal lobe dementia. International Journal of Qualitative Studies on Health and Wellbeing, 8, p.10.3402/qhw.v8i0.19860. Available at: http://www.ncbi.nlm.nih.gov/pmc/articles/PMC3578947/.

Snilstveit, B., Oliver, S. \& Vojtkova, M., 2012. Narrative approaches to systematic review and synthesis of evidence for international development policy and practice. Journal of Development Effectiveness, 4(3), pp.409-429. Available at: https://doi.org/10.1080/19439342.2012.710641.

World Health Organisation, 2012. Dementia: a public health priority., World Health Organisation. 


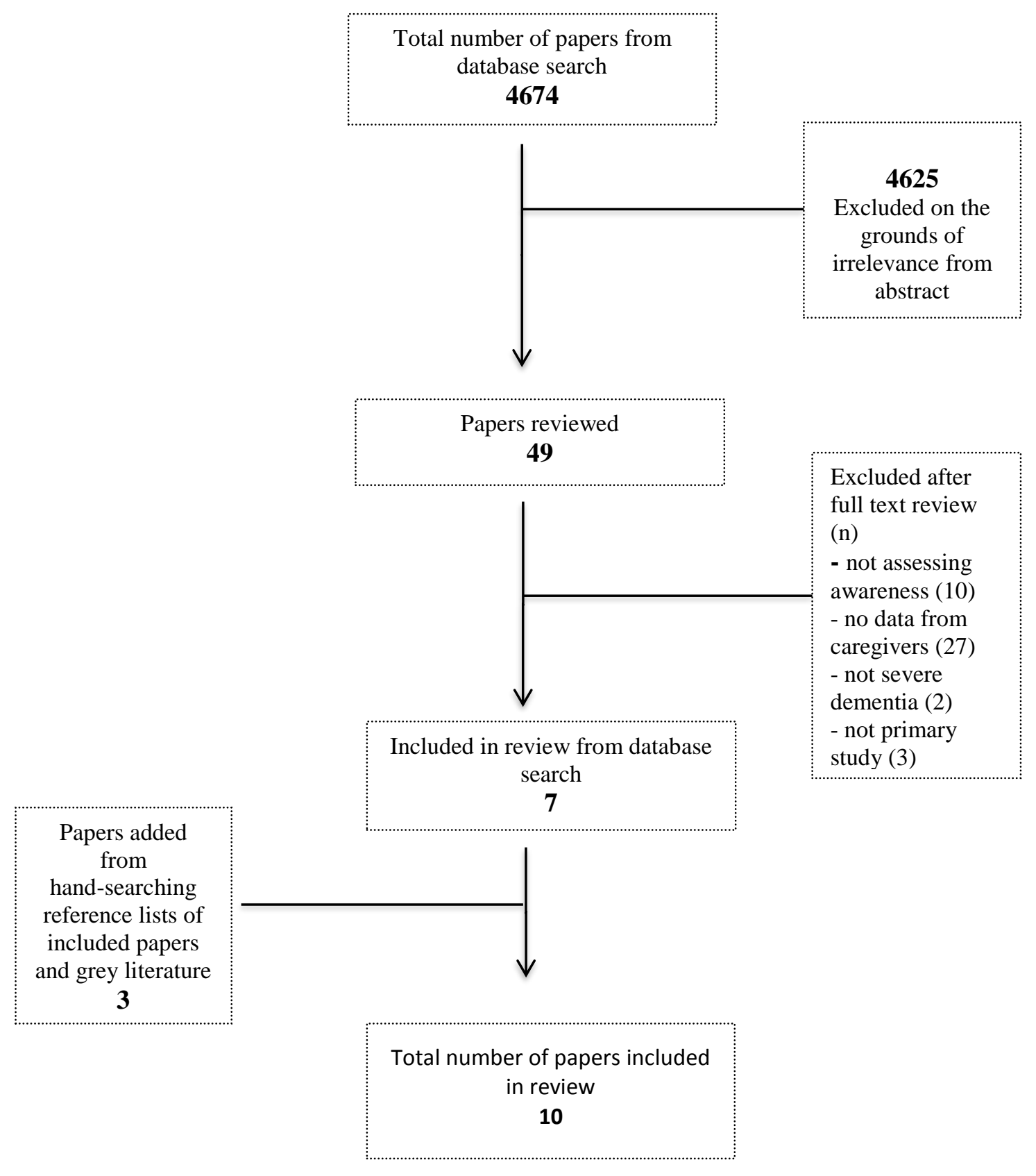

Figure 1: Flowchart of studies identified and included in the review 
Table 1: Summary of included studies

\begin{tabular}{|c|c|c|c|c|c|c|c|}
\hline Study & Design & Data collection & Data analysis & Sample size & $\begin{array}{c}\text { Sample } \\
\text { characteristics }\end{array}$ & $\begin{array}{l}\text { Care setting and } \\
\text { patient group }\end{array}$ & Location \\
\hline $\begin{array}{l}\text { Berg, A. et al., } \\
\text { (1998) }\end{array}$ & $\begin{array}{c}\text { Qualitative } \\
\text { component of larger } \\
\text { interventional study }\end{array}$ & $\begin{array}{c}2 \text { open ended, } \\
\text { unstructured } \\
\text { interviews per } \\
\text { participant (pre } \\
\text { and post } \\
\text { intervention }\end{array}$ & $\begin{array}{c}\text { Phenomenological } \\
\text { hermeneutic }\end{array}$ & 13 & nurses & $\begin{array}{l}\text { Psychogeriatric ward } \\
\text { (severe dementia) }\end{array}$ & Sweden \\
\hline $\begin{array}{l}\text { Clare, L. et al } \\
\text { (2013) }\end{array}$ & $\begin{array}{c}\text { Qualitative } \\
\text { component of } \\
\text { interventional study }\end{array}$ & $\begin{array}{c}\text { Unstructured } \\
\text { interviews with } \\
\text { participating care } \\
\text { staff and field notes } \\
\text { made by } \\
\text { researchers (pre } \\
\text { and post } \\
\text { intervention) }\end{array}$ & Thematic analysis & 64 & $\begin{array}{c}\text { 'permanent care } \\
\text { staff' }\end{array}$ & $\begin{array}{l}\text { Privately owned care } \\
\text { homes ( } 6 \text { specialist } \\
\text { dementia care and } 2 \\
\text { mixed group of older } \\
\text { people) }\end{array}$ & UK \\
\hline $\begin{array}{c}\text { Alnes, R.E et al } \\
\text { (2011) }\end{array}$ & Qualitative & $\begin{array}{l}12 \text { semi-structured } \\
\text { interviews and } 4 \\
\text { focus groups }\end{array}$ & Content analysis & 26 & $\begin{array}{l}\text { Enrolled nurses (16), } \\
\text { registered nurses (7) } \\
\text { and healthcare } \\
\text { assistants (3) }\end{array}$ & $\begin{array}{l}4 \text { Dementia specific } \\
\text { care units (severe } \\
\text { dementia) }\end{array}$ & Norway \\
\hline $\begin{array}{l}\text { Hansebo, G. et al } \\
\text { (2001) }\end{array}$ & Qualitative & $\begin{array}{l}3 \text { stimulated recall, } \\
\text { personal interviews } \\
\text { with carers }\end{array}$ & $\begin{array}{l}\text { Phenomenological } \\
\text { hermeneutic }\end{array}$ & 4 & $\begin{array}{c}\text { Nursing assistants } \\
(2) \\
\text { Enrolled nurses (2) }\end{array}$ & $\begin{array}{l}\text { Nursing home (mainly } \\
\text { severe dementia) }\end{array}$ & Sweden \\
\hline Karger, C (2018) & Qualitative & $\begin{array}{l}\text { Semi-structured } \\
\text { interviews during } \\
\text { focus groups }\end{array}$ & Content analysis & 17 & $\begin{array}{c}\text { Caregivers } \\
\text { (nurses and certified } \\
\text { geriatric caregivers }\end{array}$ & $\begin{array}{c}\text { Nursing home } \\
\text { Acute hospital, } \\
\text { (advanced } \\
\text { Alzheimer's disease) }\end{array}$ & Germany \\
\hline $\begin{array}{c}\text { Normann, H.K. et } \\
\text { al (1998) }\end{array}$ & Qualitative & $\begin{array}{c}\text { One off, semi- } \\
\text { structured personal } \\
\text { interview }\end{array}$ & Content analysis & 20 & $\begin{array}{c}\text { Licensed practical } \\
\text { nurses (16), } \\
\text { registered nurses (4) }\end{array}$ & $\begin{array}{l}3 \text { Nursing homes } \\
\text { (severe dementia) }\end{array}$ & Norway \\
\hline $\begin{array}{l}\text { Pasman } \mathrm{H} \text { et al } \\
\text { (2003) }\end{array}$ & $\begin{array}{c}\text { Qualitative } \\
\text { component of } \\
\text { observational study }\end{array}$ & $\begin{array}{c}\text { Interviews } \\
\text { following } \\
\text { observation }\end{array}$ & $\begin{array}{c}\text { Constant comparison } \\
\text { analysis }\end{array}$ & 46 & Nurses (46) & $\begin{array}{l}2 \text { Nursing Homes } \\
\text { (severe dementia) }\end{array}$ & Netherlands \\
\hline $\begin{array}{l}\text { Quinn, C. et al } \\
\text { (2014) }\end{array}$ & $\begin{array}{l}\text { Qualitative } \\
\text { component of larger } \\
\text { interventional study }\end{array}$ & Four focus groups & Thematic analysis & 23 & $\begin{array}{c}\text { Care staff }(12), \\
\text { comprising of } 1 \\
\text { manager, } 1 \text { nurse } \\
\text { and } 10 \text { care } \\
\text { assistants., and } \\
\text { family members } \\
\text { (11). }\end{array}$ & $\begin{array}{c}\text { Nursing homes } \\
\text { (severe dementia) }\end{array}$ & UK \\
\hline $\begin{array}{c}\text { Rasmussen, H., } \\
\text { Hellzen, O (2013) }\end{array}$ & Qualitative & $\begin{array}{c}\text { Semi-structured } \\
\text { personal interview }\end{array}$ & $\begin{array}{c}\text { Phenomenological } \\
\text { hermeneutic }\end{array}$ & 10 & $\begin{array}{c}\text { Healthcare staff } \\
\text { (including doctors, }\end{array}$ & $\begin{array}{l}\text { Psychiatric geriatric } \\
\text { unit within a nursing }\end{array}$ & Norway \\
\hline
\end{tabular}




\begin{tabular}{|c|c|c|c|c|c|c|c|}
\hline & & & & & $\begin{array}{l}\text { nurses and social } \\
\text { workers, exact } \\
\text { composition not } \\
\text { stated) }\end{array}$ & $\begin{array}{l}\text { home (frontal lobe } \\
\text { dementia, likely } \\
\text { severe) }\end{array}$ & \\
\hline $\begin{array}{l}\text { Nicholls, D. et al } \\
\text { (2013) }\end{array}$ & $\begin{array}{c}\text { Qualitative } \\
\text { component of mixed } \\
\text { methods } \\
\text { intervention study }\end{array}$ & $\begin{array}{l}\text { Semi-structured } \\
\text { interview with } \\
\text { focus groups }\end{array}$ & Thematic analysis & 20 & $\begin{array}{c}\text { Registered nurses } \\
\text { (12) } \\
\text { Nursing assistants } \\
\text { (8) }\end{array}$ & $\begin{array}{c}3 \text { Nursing homes } \\
\text { (advanced dementia) }\end{array}$ & Australia \\
\hline
\end{tabular}


Table 2. Thematic analysis- Key themes and sub-themes with supporting studies

\begin{tabular}{|c|c|}
\hline $\begin{array}{l}\text { Key themes and sub-themes identified within } \\
\text { the narrative synthesis }\end{array}$ & Supporting studies \\
\hline 1.1 Awareness of the self & $\begin{array}{c}\text { Berg et al (1998), Normann et al (1998), } \\
\text { Rasmussen and Hellzen (2013), Quinn et al } \\
\text { (2014). Nicholls (2013) }\end{array}$ \\
\hline 1.2 Social Awareness & $\begin{array}{c}\text { Hansebo and Kihlgren (2001), Clare et al (2013), } \\
\text { Quinn et al (2014). Nicholls (2013), Karger } \\
\text { (2018) }\end{array}$ \\
\hline 1.3 Awareness of the environment & Normann et al (1998), Quinn et al (2014) \\
\hline \multicolumn{2}{|l|}{$\begin{array}{l}\text { 2. Professional caregiver's beliefs about what } \\
\text { influences the expression of awareness in } \\
\text { advanced dementia }\end{array}$} \\
\hline 2.1 Disease progression & Berg et al (1998) \\
\hline 2.2 Environmental Factors & Quinn et al (2014) \\
\hline 2.3 Caregiver factors & $\begin{array}{c}\text { Berg et al (1998), Normann et al (1998), Hansebo } \\
\text { and Kihlgren (2001), Alnes et al (2011), } \\
\text { Rasmussen and Hellzen (2013), Clare et al (2013), } \\
\text { Quinn et al (2014) }\end{array}$ \\
\hline 2.4. Fluctuation & $\begin{array}{c}\text { Einang et al (2011), Rasmussen and Hellzen } \\
\text { (2013), Quinn et al (2014) }\end{array}$ \\
\hline \multicolumn{2}{|l|}{$\begin{array}{l}\text { 3. Professional caregiver's practice in } \\
\text { assessment of awareness in advanced } \\
\text { dementia }\end{array}$} \\
\hline 3.1. Assessment techniques and approach & $\begin{array}{c}\text { Berg et al (1998), Hansebo and Kihlgren (2001), } \\
\text { Clare et al (2013), Quinn et al (2014) Pasman et al } \\
\text { (2003), Karger (2018) }\end{array}$ \\
\hline $\begin{array}{l}\text { 3.2. Perceived impact of training in } \\
\text { assessment of awareness }\end{array}$ & $\begin{array}{l}\text { Hansebo and Kihlgren (2001), Alnes et al (2011), } \\
\text { Clare et al (2013) }\end{array}$ \\
\hline $\begin{array}{l}\text { 4. Perceived Impact of episodes of increased } \\
\text { awareness on people with advanced dementia } \\
\text { and caregivers }\end{array}$ & $\begin{array}{c}\text { Normann et al (1998), Alnes et al (2011), } \\
\text { Rasmussen and Hellzen (2013), Quinn et al } \\
(2014)\end{array}$ \\
\hline
\end{tabular}


